\title{
Saturated fat supplementation interacts with dietary forage neutral detergent fiber content during the immediate postpartum and carryover periods in Holstein cows: Production responses and digestibility of nutrients
}

\author{
P. Piantoni, A. L. Lock, and M. S. Allen ${ }^{1}$ \\ Department of Animal Science, Michigan State University, East Lansing 48824
}

\begin{abstract}
Forty-eight multiparous cows were used in a randomized complete block design experiment with a $2 \times 2$ factorial arrangement of treatments to determine the interaction between a highly saturated free FA supplement (SFFA) and dietary forage neutral detergent fiber (fNDF) content on production responses and nutrient digestibility of dairy cows in the postpartum period. Treatment diets were offered from 1 to $29 \mathrm{~d}$ postpartum (postpartum period; PP) and contained 20 or $26 \%$ fNDF (50:50 corn silage:alfalfa silage and hay, dry matter basis) and 0 or 2\% SFFA [Energy Booster 100 (Milk Specialties Global, Eden Prairie, MN); 96.1\% FA: $46.2 \%$ C18:0 and 37.0\% C16:0]. From 30 to $71 \mathrm{~d}$ postpartum (carryover period), a common diet $(\sim 23 \%$ fNDF, $0 \%$ SFFA) was offered to all cows to evaluate carryover effects of the treatment diets early in lactation. During the PP, higher fNDF decreased dry matter intake (DMI) by $2.0 \mathrm{~kg} / \mathrm{d}$, whereas SFFA supplementation increased it by $1.4 \mathrm{~kg} / \mathrm{d}$. In addition, high fNDF with $0 \%$ SFFA decreased DMI compared with the other diets and this difference increased throughout the PP. Treatments did not affect $3.5 \%$ fat-corrected milk yield during the PP but did during the carryover period when SFFA supplementation decreased $3.5 \%$ fat-corrected milk yield for the low-fNDF diet (51.1 vs. $58.7 \mathrm{~kg} / \mathrm{d}$ ), but not for the high-fNDF diet ( 58.5 vs. $58.0 \mathrm{~kg} / \mathrm{d}$ ). During the PP, lower fNDF and SFFA supplementation decreased body condition score loss. A tendency for an interaction between fNDF and SFFA indicated that low fNDF with $2 \%$ SFFA decreased body condition score loss compared with the other diets $(-0.49$ vs. -0.89$)$. During the PP, lower fNDF and $2 \%$ SFFA supplementation decreased feed efficiency $(3.5 \%$ fat-corrected milk/DMI) by 0.30 and 0.23 units, respectively. The low-fNDF diet with $2 \%$ SFFA decreased feed efficiency
\end{abstract}

Received August 28, 2014.

Accepted December 15, 2014.

${ }^{1}$ Corresponding author: allenm@msu.edu compared with other diets early in the PP, but this difference decreased over time. Supplementation of SFFA in the PP favored energy partitioning to body reserves and limited DMI depression for the high-fNDF diet, which might allow higher-fNDF diets to be fed to cows in the PP. However, SFFA supplemented in the low-fNDF diet during the PP affected production negatively in the carryover period. Dietary fNDF and SFFA interacted, affecting performance in the PP with carryover effects when cows were fed a common diet in early lactation.

Key words: dietary forage neutral detergent fiber, early lactation, free fatty acid, postpartum, prilled fat

\section{INTRODUCTION}

Following parturition cows enter a period of negative energy balance because they cannot consume enough DM to support lactation. Approaches to increase energy intake of postpartum cows include increasing the energy density of the diet by substituting starch for forage fiber or by fat supplementation. However, because of greater ruminal fermentation from high starch and less buffering from low-forage, high-starch diets might increase the risk of ruminal acidosis and displaced abomasum (Allen and Piantoni, 2013). Different FA, on the other hand, can affect metabolism and animal response differently. For example, unsaturated FA can depress feed intake (Allen, 2000), modulate insulin action (Pires and Grummer, 2008), and alter ruminal biohydrogenation, which can potentially induce milk fat depression (Baumgard et al., 2002) and increase energy partitioning to body reserves (Harvatine and Allen, 2006a; Harvatine et al., 2009). In contrast, SFA are considered to be inert in the rumen (Grummer, 1988), have little effect on DMI (Allen, 2000), and usually increase milk fat output (Wang et al., 2010; Lock et al., 2013; Piantoni et al., 2013). Variation has been observed among responses to FA supplements, and this is likely related to the FA profiles and physical form of the fat supplements, diet composition, and physiological states of cows. 
Scant research is available on production responses to diets fed in the postpartum period, especially regarding optimal forage level, fat supplementation, and their interaction. Rabelo et al. (2003) reported that a low forage-to-concentrate ratio (F:C) diet (40:60; $25 \%$ $\mathrm{NDF}$ ) fed during the first $20 \mathrm{~d}$ postpartum tended to increase DMI (16.5 vs. $15.4 \mathrm{~kg} / \mathrm{d}$ ) and increased calculated energy intake (27.7 vs. $25.1 \mathrm{Mcal} / \mathrm{d}$ ) compared with a high-F:C diet (60:40; 30\% NDF). Beam and Butler (1998) reported that a highly saturated ( $\geq 85 \%$ saturated) free FA supplemented at $2.6 \%$ of diet DM in a $45 \%$ forage diet ( $~ 33 \% \mathrm{NDF})$ decreased yields of milk and $4 \%$ FCM during the first 4 wk postpartum and increased them during the following 2 wk on experiment. Importantly, Weiss and Pinos-Rodríguez (2009) reported that the same FA supplement used by Beam and Butler (1998), fed at 2.25\% of diet DM from 21 to $126 \mathrm{~d}$ postpartum, affected energy partitioning differently depending on forage NDF (fNDF) content of the diets. In that experiment, supplemental fat increased BCS with no change in milk yield when supplemented in a 25\% fNDF diet (60:40 F:C), but increased milk yield and DMI with no change in BCS when supplemented in a $17 \%$ fNDF diet (40:60 F:C).

Although benefits of supplementing a highly saturated free $\mathrm{FA}$ to cows in the immediate postpartum period were not identified in the experiment reported by Beam and Butler (1998), the interaction between the same FA supplement and dietary fNDF content reported by Weiss and Pinos-Rodríguez (2009) on energy partitioning in early lactation cows deserves further investigation. Our objectives were to determine the interaction between a highly saturated free FA supplement and dietary fNDF content on yields of milk and milk components, intake, and nutrient digestibility of dairy cows in the postpartum period and to evaluate carryover effects of the treatment diets early in lactation. We hypothesized that the saturated free FA supplement would increase BCS when added to the high-fNDF diet and milk yield when added to the low-fNDF diet during the postpartum period considering results reported by Weiss and Pinos-Rodríguez (2009) with cows in early lactation.

\section{MATERIALS AND METHODS}

\section{Animal Housing and Care}

All experimental procedures were approved by the Institutional Animal Care and Use Committee at Michigan State University (East Lansing). The experiment began on September 30, 2011, and finished on May 1, 2012. Each cow was housed in the same tiestall, assigned by parturition order, throughout the entire treatment period. Cows were fed once daily $(1000 \mathrm{~h})$ at 120 and $110 \%$ of expected intake during the treatment and carryover periods, respectively, and milked twice daily $(0400$ and $1430 \mathrm{~h})$. The amounts of feed offered and orts were weighed for each cow daily. Standard reproduction and health herd checks and breeding practices were maintained during this study.

\section{Design and Treatment Diets}

Forty-eight multiparous Holstein cows at the Michigan State University Dairy Field Laboratory were used in a randomized complete block design experiment with a $2 \times 2$ factorial arrangement of treatments with 12 cows per treatment. Cows were blocked by date of parturition (within $90 \mathrm{~d}$ ), BCS (up to 1 unit difference using a 5 -point scale, where $1=$ thin and $5=$ fat; Wildman et al., 1982), and previous lactation 305-d matureequivalent milk production (within $5,500 \mathrm{~kg}$ ). The BCS used to block cows was the last measurement before parturition. Cows within each block were randomly assigned to treatment on the expected parturition date. Treatment diets were offered from 1 to $29 \mathrm{~d}$ postpartum (postpartum period; PP). Treatments contained 20 or $26 \%$ fNDF and 0 or $2 \%$ saturated free FA supplement [SFFA; Energy Booster 100 (Milk Specialties Global, Eden Prairie, MN); $96.1 \%$ FA: $46.2 \%$ C18:0 and 37.0\% C16:0]. Desired fNDF content of the treatment diets was attained by altering proportions of forages (alfalfa and corn silages and alfalfa hay) and concentrates (corn grain and soybean meal). Starch content was $\sim 24 \%$ for the low-fNDF diets and $\sim 17.5 \%$ for the high-fNDF diets, and dietary CP content was held constant across diets. The FA supplement was added at $2 \%$ of diet DM, replacing $2 \%$ of soyhulls in the $0 \%$ SFFA diet. Treatment diets were mixed daily in a tumble mixer and were fed from the morning following parturition. From d 30 to 71 postpartum (carryover period), all cows were offered a common diet, mixed daily in a mixer wagon. The ingredient and nutrient composition of the diets fed as TMR, including a close-up ration for reference, are described in Table 1. All rations were formulated to meet or exceed cows predicted requirements for protein, minerals, and vitamins according to NRC (2001).

\section{Data and Sample Collection}

All samples and body measurements were collected or recorded on the same day of the week during the entire experiment (d 5, 12, 19, 26, 33, 40, 47, 54, 61, and 68 postpartum), so all collection days are $\pm 3 \mathrm{~d}$ relative to the first day on the treatment diet. Milk yield and feed offered and refused were recorded daily throughout the entire experiment. Samples of all diet ingredients (0.5 
Table 1. Ingredient and nutrient composition of close-up, treatment, and carryover diets

\begin{tabular}{|c|c|c|c|c|c|c|}
\hline \multirow[b]{2}{*}{ Item } & \multirow[b]{2}{*}{$\begin{array}{l}\text { Close-up } \\
\text { diet }\end{array}$} & \multicolumn{4}{|c|}{ Treatment $\operatorname{diet}^{1}$} & \multirow[b]{2}{*}{$\begin{array}{c}\text { Carryover } \\
\text { diet }\end{array}$} \\
\hline & & $0 \%$ SFFA & $2 \%$ SFFA & $0 \%$ SFFA & $2 \%$ SFFA & \\
\hline \multicolumn{7}{|l|}{ Ingredient, $\%$ of DM } \\
\hline Corn silage & 42.5 & 21.9 & 21.7 & 28.2 & 28.4 & 29.9 \\
\hline Grass hay & 25.4 & - & - & - & - & - \\
\hline Dry ground corn & 7.95 & 24.4 & 24.2 & 12.7 & 12.5 & 23.7 \\
\hline Soybean meal & 14.0 & 12.4 & 12.8 & 11.1 & 11.6 & 9.58 \\
\hline Cottonseed with lint & - & - & - & - & - & 6.60 \\
\hline SoyChlor $^{2}$ & 2.29 & - & - & - & - & - \\
\hline SoyPlus $^{2}$ & - & 4.90 & 4.90 & 4.86 & 4.87 & 3.67 \\
\hline Soyhulls & - & 9.55 & 7.49 & 9.44 & 7.55 & - \\
\hline Vitamin-mineral mix $^{3,4,5}$ & 7.84 & 5.42 & 5.41 & 5.43 & 5.42 & 4.45 \\
\hline Forage NDF, $\%$ of DM & 35.9 & 20.0 & 19.9 & 25.9 & 25.8 & 22.7 \\
\hline Starch, \% of DM & 18.1 & 24.2 & 23.8 & 17.6 & 17.3 & 25.6 \\
\hline $\mathrm{CP}, \%$ of $\mathrm{DM}$ & 13.6 & 17.4 & 17.4 & 17.4 & 17.3 & 17.7 \\
\hline Ether extract, \% of DM & 2.39 & 2.83 & 4.61 & 2.74 & 4.53 & 3.92 \\
\hline Gross energy, Mcal/kg of DM & $\mathrm{ND}^{7}$ & 4.39 & 4.49 & 4.42 & 4.52 & ND \\
\hline \multicolumn{7}{|c|}{ Particle size distribution, ${ }^{8} \%$ of TMR (as DM) retained on sieves } \\
\hline Upper sieve, particles $>19 \mathrm{~mm}$ & 24.9 & 7.16 & 8.40 & 10.7 & 10.8 & 13.1 \\
\hline Middle sieve, particles $>8 \mathrm{~mm}$ & 31.8 & 35.2 & 32.3 & 38.8 & 39.8 & 38.4 \\
\hline Bottom sieve, particles $>1.18 \mathrm{~mm}$ & 37.4 & 42.5 & 42.0 & 37.6 & 36.3 & 38.4 \\
\hline Bottom pan, particles $<1.18 \mathrm{~mm}$ & 5.92 & 15.2 & 17.3 & 12.9 & 13.1 & 10.1 \\
\hline
\end{tabular}

${ }^{1}$ Treatment diets were either 20 or $26 \%$ forage NDF (fNDF) and 0 or $2 \%$ saturated free FA supplement (SFFA), and were fed from 1 to $29 \mathrm{~d}$ postpartum. Close-up diet was fed from d -14 of expected calving date until calving date. Carryover diet was fed from 30 to $71 \mathrm{~d}$ postpartum. ${ }^{2}$ West Central Soy, Ralston, IA

${ }^{3}$ Vitamin-mineral mix for the close-up diet contained (DM basis): $54.8 \%$ SoyChlor, $13.9 \%$ limestone, $10.0 \%$ rumen-protected choline, $8.8 \%$ dicalcium phosphate, $4.2 \%$ magnesium sulfate, $1.8 \%$ salt, $1.8 \%$ yeast, $4.4 \%$ trace minerals and vitamins, and $0.3 \%$ selenium yeast $600(600$ mg of $\mathrm{Se} / \mathrm{kg})$.

${ }^{4}$ Vitamin-mineral mix for the treatment diets contained (DM basis): $27.9 \%$ molasses, $15.3 \%$ limestone, $12.2 \%$ sodium bicarbonate, $11.8 \%$ blood meal, $8.7 \%$ dicalcium phosphate, $6.1 \%$ trace minerals and vitamins, $5.7 \%$ rumen-protected choline, $4.4 \%$ magnesium sulfate, $3.9 \%$ salt, $2.7 \%$ animal fat, $0.9 \%$ yeast, and $0.4 \%$ selenium yeast $600(600 \mathrm{mg}$ of $\mathrm{Se} / \mathrm{kg})$.

${ }^{5}$ Vitamin-mineral mix for the carryover diet contained (DM basis): $30.1 \%$ limestone, $25.3 \%$ sodium bicarbonate, $10.1 \%$ salt, $7.1 \%$ urea, $6 \%$ potassium chloride, $6 \%$ dicalcium phosphate, $5.7 \%$ animal fat, $5.7 \%$ magnesium sulfate, $3.9 \%$ trace minerals and vitamins, and $0.2 \%$ selenium yeast $600(600 \mathrm{mg}$ of $\mathrm{Se} / \mathrm{kg})$.

${ }^{6}$ Energy Booster 100 (Milk Specialties Global, Eden Prairie, MN): 96.1\% FA (46.2\% C18:0, 37.0\% C16:0, 3.96\% C18:1 cis-9, 2.66\% C14:0, and others $<2 \%$ each).

${ }^{7}$ Not determined.

${ }^{8}$ Particle size of TMR was evaluated with the Penn State Forage Particle Separator (NASCO, Fort Atkinson, WI).

$\mathrm{kg})$ and orts from each cow $(\sim 12.5 \%)$ were collected weekly during the entire experiment and stored in plastic bags at $-20^{\circ} \mathrm{C}$ until processed. On $\mathrm{d} 5,12,19$, and 26 of the PP, fecal samples (500 g) were collected every $6 \mathrm{~h}$, representing every $6 \mathrm{~h}$ of a 24 -h period to account for diurnal variation, for nutrient digestibility analysis. Feces were stored in a sealed plastic cup at $-20^{\circ} \mathrm{C}$ until dried. During the entire experiment, milk samples were collected weekly at each milking and stored with preservative at $4^{\circ} \mathrm{C}$ for component analysis (Universal Lab Services, East Lansing, MI). An additional milk sample was collected at each milking on d 5, 12, 19, and
26 of the $\mathrm{PP}$ and stored without preservative at $-20^{\circ} \mathrm{C}$ for determination of FA profile. Body weight and BCS were recorded weekly from $\mathrm{d}-9$ of expected parturition day and during the entire experiment. Body condition was scored by 3 trained investigators on a 5 -point scale, as described by Wildman et al. (1982).

\section{Sample Analysis}

Feed, orts, and fecal samples were dried in a $55^{\circ} \mathrm{C}$ forced-air oven for $72 \mathrm{~h}$ to determine DM content. Before drying, ingredients from only the close-up and 
carryover diets were composited; concentrates were composited every $4 \mathrm{wk}$ and forages every $2 \mathrm{wk}$. All feed ingredients of the treatment diets were analyzed by week for nutrient composition. Orts were dried to calculate DMI on collection days, but only orts collected during the PP were processed further and analyzed for nutrient composition. Once dried, samples of feed ingredients, and orts and feces collected during the PP, were ground in a Wiley mill (1-mm screen; Arthur H. Thomas Co., Philadelphia, PA) and analyzed for ash, NDF, indigestible NDF, CP, and starch. All samples taken during the $\mathrm{PP}$ were also analyzed for gross energy. Feed ingredients collected during the PP were composited by month and analyzed for ether extract. Feces were composited by cow by day on an equal DM basis before analysis. All nutrients are expressed as percentages of DM, determined by drying at $105^{\circ} \mathrm{C}$ in a forcedair oven for more than $8 \mathrm{~h}$. Ash content was determined after $5 \mathrm{~h}$ of oxidation at $500^{\circ} \mathrm{C}$. Content of $\mathrm{NDF}$ was determined according to Mertens (2002). Indigestible NDF, which was used as an internal marker to estimate fecal output and nutrient digestibility (Cochran et al., 1986), was estimated as NDF residue after $240 \mathrm{~h}$ of in vitro fermentation (Goering and Van Soest, 1970); flasks were reinoculated at $120 \mathrm{~h}$ to ensure a viable microbial population. Ruminal fluid for the in vitro incubations was collected from a nonpregnant dry cow fed dry hay only. Crude protein was determined according to Hach et al. (1987). Starch was gelatinized with sodium hydroxide and hydrolyzed using an enzymatic method (Karkalas, 1985); glucose was then measured using a glucose oxidase method (PGO Enzyme Product No. P7119; Sigma Chemical Co., St. Louis, MO) and by determination of absorbance with a microplate reader (SpectraMax 190; Molecular Devices Corp., Sunnyvale, CA). Ether extract was determined according to AOAC International (2005; method 920.39). Gross energy was assayed by bomb calorimeter (Parr Instrument Inc., Moline, IL). Oven-dried samples of all 6 TMR fed during the experiment (close-up, treatment, and carryover diets) were composited by month and evaluated for particle size distribution using the Penn State Forage Particle Separator (NASCO, Fort Atkinson, WI) in duplicate (Lammers et al., 1996).

Milk samples stored with preservative were analyzed for fat, true protein, lactose, MUN, and SCC by infrared spectroscopy (AOAC International, 1997) by the Michigan Herd Improvement Association (Universal Lab Services). Milk samples stored without preservative were composited by milk fat yield and centrifuged at $17,800 \times g$ for $30 \mathrm{~min}$ at $4^{\circ} \mathrm{C}$ to collect the fat cake. Lipids were extracted according to Hara and Radin (1978) and FAME were prepared according to Christie (1989). Quantification of FAME was performed using a
GC-2010 Plus gas chromatograph (Shimadzu, Kyoto, Japan) as described by Lock et al. (2013). A total of approximately 80 individual FA were quantified per sample and used for summations. Yields of individual FA in milk fat were calculated by correcting for glycerol content according to Schauff et al. (1992), and other milk lipid classes according to Glasser et al. (2007).

\section{Statistical Analysis}

Data were analyzed separately for PP (from 1 to 29 d postpartum) and for the carryover period (from 30 to $71 \mathrm{~d}$ postpartum). All weekly data were analyzed using the MIXED procedure of SAS v.9.2 (SAS Institute Inc., Cary, NC) according to the following model with repeated measures:

$$
\begin{aligned}
\mathrm{Y}_{\mathrm{ijklmn}} & =\mu+\mathrm{B}_{\mathrm{i}}+\mathrm{C}\left(\mathrm{B}_{\mathrm{i}} \mathrm{K}_{\mathrm{k}} \mathrm{S}_{1}\right)_{\mathrm{j}}+\mathrm{K}_{\mathrm{k}}+\mathrm{S}_{1}+\mathrm{K}_{\mathrm{k}} \mathrm{S}_{1}+\mathrm{T}_{\mathrm{m}} \\
& +\mathrm{K}_{\mathrm{k}} \mathrm{T}_{\mathrm{m}}+\mathrm{S}_{\mathrm{l}} \mathrm{T}_{\mathrm{m}}+\mathrm{K}_{\mathrm{k}} \mathrm{S}_{\mathrm{l}} \mathrm{T}_{\mathrm{m}}+\mathrm{J}_{\mathrm{n}}+\mathrm{e}_{\mathrm{ijklmn}},
\end{aligned}
$$

where $\mu=$ overall mean, $B_{i}=$ random effect of block ( $\mathrm{i}$ $=1$ to 12$), \mathrm{C}\left(\mathrm{B}_{\mathrm{i}} \mathrm{K}_{\mathrm{k}} \mathrm{S}_{1}\right)_{\mathrm{j}}=$ random effect of cow $(\mathrm{j}=1$ to 4) within block and treatment diet, $\mathrm{K}_{\mathrm{k}}=$ fixed effect of fNDF ( $k=1$ to 2$), S_{1}=$ fixed effect of SFFA ( $1=1$ to 2), $\mathrm{K}_{\mathrm{k}} \mathrm{S}_{1}=$ interaction between fNDF and SFFA, $\mathrm{T}_{\mathrm{m}}=$ fixed effect of week ( $\mathrm{m}=1$ to 4$), \mathrm{K}_{\mathrm{k}} \mathrm{T}_{\mathrm{m}}=$ interaction between fNDF and week, $\mathrm{S}_{1} \mathrm{~T}_{\mathrm{m}}=$ interaction between SFFA and week, $\mathrm{K}_{\mathrm{k}} \mathrm{S}_{1} \mathrm{~T}_{\mathrm{m}}=$ interaction between fNDF, SFFA, and week, $\mathrm{J}_{\mathrm{n}}=$ random effect of Julian date, and $\mathrm{e}_{\mathrm{ijk} k \mathrm{mn}}=$ residual error. Unless otherwise specified, first-order autoregressive was the covariate structure used for analysis because it resulted in the lowest Bayesian information criterion for most of the variables measured. Interactions with time were removed from the model when nonsignificant and a reduced model was used to determine treatment effects. However, all interactions were included in the tables for informational purposes.

Treatment differences within week were analyzed using the GLIMMIX procedure of SAS version 9.2 (SAS Institute) and the SLICE option. The model included the random effects of block and cow nested within block and treatment and the fixed effects of fNDF and SFFA and their interaction. The Bonferroni adjustment was applied to decrease the probability of type I error when multiple comparisons were done. Cumulative milk yield and DMI and BW and BCS changes were analyzed using the MIXED procedure of SAS version 9.2 (SAS Institute) with the same model used in the GLIMMIX procedure.

Normality of the residuals was checked with normal probability and box plots and homogeneity of variances with plots of residuals versus predicted values. Signifi- 
Table 2. Least squares means for previous lactation 305-d mature-equivalent milk yield (305-d MEq), and precalving BCS (5-point scale) and BW per treatment group ${ }^{1}$

\begin{tabular}{|c|c|c|c|c|c|c|}
\hline \multirow[b]{2}{*}{ Item } & \multicolumn{2}{|c|}{$20 \%$ fNDF } & \multicolumn{2}{|c|}{$26 \%$ fNDF } & \multirow[b]{2}{*}{$\mathrm{SE}$} & \multirow[b]{2}{*}{$P$-value } \\
\hline & $0 \%$ SFFA & $2 \%$ SFFA & $0 \%$ SFFA & $2 \%$ SFFA & & \\
\hline 305-d MEq, kg & 13,558 & 12,894 & 14,081 & 13,323 & 543 & 0.48 \\
\hline BCS & 3.40 & 3.53 & 3.19 & 3.45 & 0.136 & 0.33 \\
\hline $\mathrm{BW}, \mathrm{kg}$ & 847 & 792 & 795 & 790 & 26.8 & 0.39 \\
\hline
\end{tabular}

${ }^{1}$ Treatment diets were either 20 or $26 \%$ forage NDF (fNDF) and 0 or $2 \%$ saturated free FA supplement (SFFA), and were fed from 1 to $29 \mathrm{~d}$ postpartum. Carryover diet was fed from 30 to $71 \mathrm{~d}$ postpartum.

cance was determined at $P \leq 0.05$ for main effects and $P \leq 0.10$ for interactions. Tendencies were determined at $P \leq 0.10$ for main effects and $P \leq 0.15$ for interactions. All cows were in apparent good health at the beginning of the study, and treatment groups were not different in terms of previous lactation 305-d matureequivalent milk production $(P=0.48)$, BW $(P=0.39)$, and precalving BCS $(P=0.33$; Table 2$)$. One of the cows on the $26 \%$ fNDF, $2 \%$ SFFA diet had a displaced abomasum and underwent surgery on d 59 of the study. Therefore, the data of the last $2 \mathrm{wk}$ and the cumulative milk yield and DMI of the carryover period were excluded from the statistical analyses. All other data were included. Table 3 summarizes all health incidents during treatment and carryover periods for reference.

\section{RESULTS}

\section{Dry Matter Intake}

During the PP, the high-fNDF diets decreased DMI by $2.0 \mathrm{~kg} / \mathrm{d}(P<0.01)$ compared with the low-fNDF diets, whereas $2 \%$ SFFA increased DMI by $1.4 \mathrm{~kg} / \mathrm{d}(P$
$=0.04$ ) compared with 0\% SFFA (Table 4). However, these treatments interacted over time; the high-fNDF diet with 0\% SFFA decreased DMI compared with the other diets and this difference increased throughout the PP (interaction $P<0.01$; Figure 1). Both the low-fNDF diet with $0 \%$ SFFA and the high-fNDF diet with $2 \%$ SFFA increased DMI at a higher rate than the other 2 diets during the PP (interaction $P<0.01$ ) and had consistently greater DMI throughout the carryover period, with greater DMI for the low-fNDF diet with $0 \%$ SFFA than the high-fNDF diet with $2 \%$ SFFA throughout the carryover period (interaction $P=0.10$; Table 5). During the PP, the high-fNDF diets decreased cumulative DMI compared with the low-fNDF diets $(P$ $<0.001$ ), but the effect on DMI tended to be greater for 0\% SFFA (106 kg, 15\%) than for 2\% SFFA (45 $\mathrm{kg}, 6.4 \%$; interaction $P=0.12$ ). The SFFA treatment increased DMI and cumulative DMI for the high-fNDF diet, but decreased DMI (interaction $P=0.10$ ) and cumulative DMI (interaction $P=0.07$ ) for the lowfNDF diet for the entire carryover period, although the difference among treatments tended to decrease as time progressed (interaction $P=0.13$ ).

Table 3. Health incidents during the treatment and carryover periods within treatment diet $^{1}$

\begin{tabular}{|c|c|c|c|c|}
\hline \multirow[b]{2}{*}{ Item } & \multicolumn{2}{|c|}{$20 \%$ fNDF } & \multicolumn{2}{|c|}{$26 \% \mathrm{fNDF}$} \\
\hline & $0 \%$ SFFA & $2 \%$ SFFA & $0 \%$ SFFA & $2 \%$ SFFA \\
\hline \multicolumn{5}{|l|}{ During treatment period } \\
\hline Fever with no apparent cause $\left(>39.5^{\circ} \mathrm{C}\right)$ & 1 & 0 & 0 & 0 \\
\hline Ketosis & 2 & 2 & 3 & 5 \\
\hline Lameness & 0 & 0 & 0 & 1 \\
\hline Mastitis & 2 & 0 & 0 & 0 \\
\hline Metritis & 1 & 0 & 0 & 0 \\
\hline Milk fever & 1 & 0 & 0 & 0 \\
\hline Retained placenta & 0 & 2 & 2 & 1 \\
\hline Udder edema & 0 & 0 & 0 & 1 \\
\hline \multicolumn{5}{|l|}{ During carryover period } \\
\hline Displaced abomasum & 0 & 0 & 0 & 1 \\
\hline Lameness (unknown origin) & 1 & 0 & 1 & 0 \\
\hline Lameness (traumatic origin) & 1 & 0 & 0 & 0 \\
\hline Mastitis & 1 & 2 & 1 & 0 \\
\hline
\end{tabular}

${ }^{1}$ Treatment diets were either 20 or $26 \%$ forage NDF (fNDF) and 0 or $2 \%$ saturated free FA supplement (SFFA), and were fed from 1 to $29 \mathrm{~d}$ postpartum. 


\section{Yields of Milk and Milk Components}

During the PP, SFFA supplementation tended to decrease milk yield by $3.1 \mathrm{~kg} / \mathrm{d}(P=0.10)$, but did not affect yields of $3.5 \%$ FCM, ECM, or cumulative milk (Table 4). Lower fNDF decreased milk yield early but increased milk yield late in the PP (interaction $P=0.09$ ). However, fNDF did not affect cumulative milk yield or yields of $3.5 \%$ FCM or ECM during the treatment period. During the carryover period, the $2 \%$ SFFA treatment tended to decrease milk yield and cumulative milk yield more for the low-fNDF diet $(8.0$ $\mathrm{kg} / \mathrm{d}$ and $358 \mathrm{~kg}$, respectively) than for the high-fNDF diet $(1.3 \mathrm{~kg} / \mathrm{d}$ and $56 \mathrm{~kg}$, respectively; interaction $P$ $\leq 0.15$; Table 5 and Figure 2). Similar interactions were observed for FCM and ECM; whereas $2 \%$ SFFA decreased $3.5 \%$ FCM by $7.6 \mathrm{~kg} / \mathrm{d}$ and ECM by 7.2 $\mathrm{kg} / \mathrm{d}$ for the low-fNDF diet, it slightly increased $3.5 \%$ FCM and ECM by $\sim 0.5 \mathrm{~kg} / \mathrm{d}$ for the high-fNDF diet (interaction $P \leq 0.10$ ). Across fNDF content of the diets, SFFA supplementation during the PP decreased milk yield by $4.7 \mathrm{~kg} / \mathrm{d}$ and cumulative milk yield by $207 \mathrm{~kg}$ (both $P=0.05$ ) during the carryover period. In contrast, fNDF content of diets fed during the PP did not have an overall effect on yields of milk, 3.5\% FCM, ECM, or cumulative milk yield during the carryover period.

During the PP, lower-fNDF diets tended to increase milk protein and decrease milk fat concentrations $(P$ $<0.10)$ but did not affect milk lactose concentration (Table 4). Fat supplementation during the PP had no effects on milk protein, fat, or lactose concentrations during the treatment period. However, during the carryover period, $2 \%$ SFFA increased milk fat concentration during most of the period (interaction $P=0.05$ ) and tended to increase milk protein concentration $(P$ $=0.09)$, whereas dietary fNDF content had no effect on milk fat or protein concentrations (Table 5). Compared with high fNDF, low fNDF decreased milk lactose concentration initially when cows were fed the common diet, but the difference between treatments tended to decrease over time (interaction $P=0.12$ ) with no overall effect through the period. Lower fNDF treatments decreased MUN concentration for 0\% SFFA (15.8 vs. $14.0 \mathrm{mg} / \mathrm{dL}$ ), but had little effect for $2 \%$ SFFA $(14.5$ vs. $14.8 \mathrm{mg} / \mathrm{dL})$ during the $\mathrm{PP}(P=0.03)$. The $2 \%$ SFFA treatment tended to decrease MUN over time compared with 0\% SFFA during the treatment period (interaction $P=0.14$ ), but differences diminished as the carryover period progressed (interaction $P=0.13$ ).

During the treatment period, low fNDF with $0 \%$ SFFA increased milk protein yield compared with the other treatments, but differences among treatments de- creased as time progressed (interaction $P=0.11$; Table 4). The lower-fNDF diets increased yield of milk lactose throughout the PP at a faster rate compared with the high-fNDF diets (interaction $P=0.10$ ), with no overall effect because lactose yield was lower for the low-fNDF diets than for the high-fNDF diets at the beginning of the period but higher at the end. Fat supplementation during the PP decreased yields of fat and protein during the carryover period only for the low-fNDF treatment by 0.26 and $0.18 \mathrm{~kg} / \mathrm{d}$, respectively (interaction $P \leq 0.10$; Table 5). During the carryover period, SFFA tended to decrease lactose yield overall $(P=0.07)$, but more so in the low-fNDF diet (interaction $P=0.15$ ).

\section{Body Condition Score and Body Weight}

During the PP, low-fNDF diets and 2\% SFFA supplementation decreased BCS loss; the effect of SFFA supplementation tended to be more pronounced for the low-fNDF diet than for the high-fNDF diet (interaction $P=0.13$; Table 4). Therefore, SFFA supplementation and lower fNDF increased BCS by 0.3 units (both $P$ $=0.02)$. Treatment differences increased over time through the period with a greater BCS loss for $0 \%$ SFFA compared with $2 \%$ SFFA (interaction $P=0.15$ ) and for low fNDF compared with high fNDF (interaction $P=0.02$ ). The effect of SFFA treatment on BCS was sustained through the carryover period, during which BCS was 0.36 units higher $(P=0.02)$ for the $2 \%$ SFFA treatment compared with the $0 \%$ SFFA treatment (Table 5). Treatment differences for fNDF continued to increase through the carryover period (interaction $P=0.10)$, which resulted in 0.52 units higher BCS for the low-fNDF treatment $(P=0.001)$. Although no overall effects of fNDF content on BW were observed during the PP, the high-fNDF treatment decreased BW at a greater rate than the low-fNDF treatment (interaction $P=0.06)$ during this period and decreased BW compared with the low-fNDF treatment $(61.5 \mathrm{~kg} ; P<$ 0.01 ) in the carryover period. Overall, and during PP, SFFA supplementation decreased BW loss, whereas higher-fNDF diets tended to increase BW loss. During the carryover period, SFFA supplementation tended to decrease BW loss regardless of dietary fNDF content.

\section{Feed Efficiency}

Lower fNDF (2.36 vs. 2.67, $P=0.01)$ and SFFA supplementation (2.40 vs. 2.63, $P=0.05)$ decreased feed efficiency (FE; 3.5\% FCM/DMI) through the PP period (Table 4). However, SFFA supplementation in the low-fNDF diet decreased FE greatly compared with the other diets early in the period and this difference 
Table 4. Effects of dietary forage NDF (fNDF) content and a saturated free FA supplement (SFFA) on DMI and production of dairy cows during the treatment period (1 to 29 d postpartum)

\begin{tabular}{|c|c|c|c|c|c|c|c|c|c|c|c|}
\hline \multirow[b]{2}{*}{ Item } & \multicolumn{2}{|c|}{$20 \%$ fNDF } & \multicolumn{2}{|c|}{$26 \%$ fNDF } & \multirow[b]{2}{*}{ SEM } & \multicolumn{6}{|c|}{$P$-value } \\
\hline & $\begin{array}{c}0 \% \\
\text { SFFA }\end{array}$ & $\begin{array}{c}2 \% \\
\text { SFFA }\end{array}$ & $\begin{array}{c}0 \% \\
\text { SFFA }\end{array}$ & $\begin{array}{c}2 \% \\
\text { SFFA }\end{array}$ & & $\mathrm{fNDF}$ & SFFA & $\begin{array}{c}\text { fNDF } \\
\times \text { SFFA }\end{array}$ & $\begin{array}{l}\text { fNDF } \\
\times \text { time }\end{array}$ & $\begin{array}{l}\text { SFFA } \\
\times \text { time }\end{array}$ & $\begin{array}{c}\mathrm{fNDF} \times \mathrm{SFFA} \\
\times \text { time }\end{array}$ \\
\hline DMI, $\mathrm{kg} / \mathrm{d}$ & 23.6 & 24.2 & 20.8 & 23.0 & 0.743 & $<0.01$ & 0.04 & 0.25 & 0.79 & 0.61 & $<0.01$ \\
\hline Cumulative DMI, $\mathrm{kg}$ & 705 & 706 & 599 & 661 & 21.0 & $<0.001$ & 0.12 & 0.12 & $\mathrm{NA}^{1}$ & $\mathrm{NA}$ & NA \\
\hline Milk & 51.2 & 45.3 & 48.2 & 47.8 & 1.89 & 0.90 & 0.10 & 0.16 & 0.09 & 0.72 & 0.22 \\
\hline Fat & 2.19 & 2.03 & 2.22 & 2.31 & 0.129 & 0.19 & 0.73 & 0.29 & 0.39 & 0.25 & 0.51 \\
\hline Protein & 1.63 & 1.51 & 1.49 & 1.53 & 0.052 & 0.23 & 0.43 & 0.13 & 0.26 & 0.77 & 0.11 \\
\hline Lactose & 2.47 & 2.20 & 2.29 & 2.31 & 0.089 & 0.67 & 0.16 & 0.11 & 0.10 & 0.58 & 0.33 \\
\hline $3.5 \% \mathrm{FCM}$ & 57.7 & 52.4 & 56.9 & 58.1 & 2.75 & 0.35 & 0.43 & 0.21 & 0.21 & 0.30 & 0.39 \\
\hline $\mathrm{ECM}$ & 56.8 & 51.6 & 55.1 & 56.4 & 2.49 & 0.52 & 0.43 & 0.18 & 0.19 & 0.32 & 0.28 \\
\hline Cumulative milk yield, $\mathrm{kg}$ & 1,453 & 1,310 & 1,375 & 1,351 & 51.8 & 0.72 & 0.12 & 0.26 & $\mathrm{NA}$ & NA & NA \\
\hline $\begin{array}{l}\text { Feed efficiency }{ }^{2} \\
\text { Milk composition } \%\end{array}$ & 2.50 & 2.22 & 2.76 & 2.57 & 0.130 & 0.01 & 0.05 & 0.71 & 0.11 & 0.14 & 0.10 \\
\hline $\begin{array}{l}\text { Milk composition, } \% \\
\text { Fat }\end{array}$ & 4.35 & 4.52 & 4.66 & 4.89 & 0.193 & 0.06 & 0.25 & 0.86 & 0.89 & 0.71 & 0.74 \\
\hline Protein & 3.27 & 3.43 & 3.14 & 3.25 & 0.088 & 0.08 & 0.13 & 0.80 & 0.24 & 0.79 & 0.68 \\
\hline Lactose & 4.83 & 4.84 & 4.74 & 4.82 & 0.042 & 0.19 & 0.22 & 0.34 & 0.80 & 0.19 & 0.90 \\
\hline MUN, mg/dL & 14.0 & 14.8 & 15.8 & 14.5 & 0.559 & 0.10 & 0.67 & 0.03 & 0.71 & 0.14 & 0.92 \\
\hline $\mathrm{SCC}, \times 1,000 / \mathrm{mL}$ & 135 & 99.5 & 61.9 & 98.6 & 34.5 & 0.27 & 0.98 & 0.28 & 0.27 & 0.28 & 0.16 \\
\hline $\mathrm{BW},{ }^{3} \mathrm{~kg}$ & 739 & 718 & 690 & 700 & 23.1 & 0.15 & 0.79 & 0.46 & 0.06 & 0.70 & 0.84 \\
\hline BW change ${ }^{4}$ & -110 & -84.9 & -126 & -107 & 10.7 & 0.06 & 0.03 & 0.79 & $\mathrm{NA}$ & $\mathrm{NA}$ & NA \\
\hline BCS & 2.86 & 3.16 & 2.55 & 2.86 & 0.154 & 0.02 & 0.02 & 0.97 & 0.02 & 0.15 & 0.69 \\
\hline BCS change ${ }^{4}$ & -0.816 & -0.490 & -0.951 & -0.903 & 0.090 & $<0.01$ & 0.04 & 0.13 & $\mathrm{NA}$ & NA & NA \\
\hline \multicolumn{12}{|c|}{$\begin{array}{l}{ }^{1} \text { Not applicable. } \\
{ }^{2} 3.5 \% \text { FCM }(\mathrm{kg} / \mathrm{d}) / \mathrm{DMI}(\mathrm{kg} / \mathrm{d}) \text {. } \\
{ }^{3} \text { Because of infinite likelihood with first-order au } \\
{ }^{4} \text { Change measured between d } 26 \text { and precalving. }\end{array}$} \\
\hline
\end{tabular}




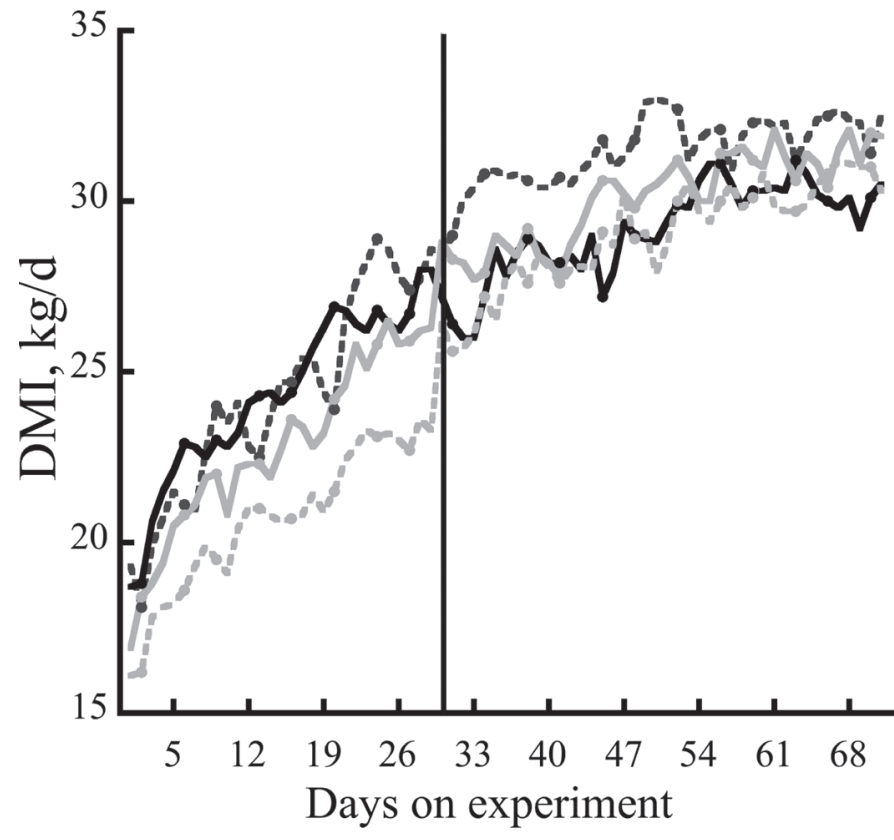

Figure 1. Effects of dietary forage NDF (fNDF) content and a saturated free FA supplement $(\mathrm{SFFA})$ on DMI $(\mathrm{kg} / \mathrm{d})$ over time during the treatment and carryover periods. Treatment diets were: $20 \%$ fNDF, 0\% SFFA (black, broken line); $20 \%$ fNDF, $2 \%$ SFFA (black, solid line); $26 \%$ fNDF, 0\% SFFA (gray, broken line); and $26 \%$ fNDF $2 \%$ SFFA (gray, solid line). Daily averages for treatment groups were calculated with the raw data of 12 cows per treatment diet during both the treatment and carryover periods $(\mathrm{n}=11$ for $26 \% \mathrm{fNDF}, 2 \%$ SFFA during the carryover period). The line on $\mathrm{d} 30$ indicates the start of the carryover period, when all cows were fed a common diet with no supplemental fat added.

in FE became smaller as time progressed (interaction $P=0.10)$. Feed efficiency during the carryover period was not affected by SFFA supplementation during the $\mathrm{PP}$, but lower fNDF during the PP continued to reduce FE during the carryover period (1.82 vs. $1.98 ; P=0.03$, Table 5).

\section{Total-Tract Digestibility During the Postpartum Period}

Overall, fat supplementation increased gross energy digestibility and total-tract $\mathrm{OM}$ digestibility (both $P \leq$ $0.05)$. The effect of fat supplementation on OM digestibility was mainly because of its effect on the low-fNDF diet (interaction $P<0.08$; Table 6 ). Both higher fNDF and $2 \%$ SFFA increased digestibility of NDF and CP, but the significant overall effect of SFFA on NDF digestibility was entirely due to its effect in the low-fNDF diet (interaction $P=0.04$ ). An interaction between fNDF and SFFA with time was detected for total-tract digestibility of starch $(P=0.02)$; whereas the highfNDF diet with $2 \%$ SFFA decreased starch digestibility over time, the low-fNDF diet with $2 \%$ SFFA increased it. Overall, higher fNDF and 2\% SFFA decreased starch digestibility (both $P \leq 0.05$ ).

\section{Milk FA Yields and Profile During the Postpartum Period}

Diets did not affect yields of palmitic acid or mixedsource FA in milk (Table 7 and Supplementary Table S1; http://dx.doi.org/10.3168/jds.2014-8798). Overall, high-fNDF diets decreased de novo but increased preformed FA yields compared with low-fNDF diets (both $P=0.02)$. Higher fNDF tended to increase stearic acid yield in milk $(P=0.06)$, and this effect was more pronounced earlier in the treatment period (interaction $P$ $=0.07$ ). Supplementation of SFFA did not affect yields of stearic acid or preformed FA during the PP overall, but increased stearic acid yield later in the period (interaction $P<0.01$ ). Diets without SFFA tended to increase preformed FA early in the treatment period, but this effect disappeared over time (interaction $P=$ 0.11). Fat supplementation increased the proportion of mixed source FA $(P<0.01)$, tended to decrease the proportion of preformed FA $(P=0.06)$, but did not affect the proportion of FA from de novo synthesis in milk (Table 7). High-fNDF diets decreased proportions of FA from mixed source and de novo synthesis, but increased proportion of preformed FA in milk (all $P \leq$ $0.05)$.

\section{DISCUSSION}

\section{Interaction Between fNDF Content and SFFA Supplementation}

Dietary treatments used in this experiment are similar to those evaluated by Weiss and Pinos-Rodríguez (2009) for cows starting $3 \mathrm{wk}$ into lactation, but our results were not entirely consistent with theirs. Regardless of dietary fNDF content, SFFA supplementation increased DMI, decreased BW loss, and tended to decrease BCS loss and milk yield during the PP. Furthermore, treatment effect on BCS loss tended to be more pronounced when SFFA was supplemented in the low-fNDF diet than in the high-fNDF diet. Therefore, during the PP, SFFA supplementation favored energy partitioning to body reserves and not milk production, especially in the low-fNDF diet. Interestingly, the diets fed during the immediate postpartum period had a tremendous carryover effect during early lactation, when cows were fed a common diet; the low-fNDF diet with $2 \%$ SFFA decreased $3.5 \%$ FCM by $\sim 7.5 \mathrm{~kg} / \mathrm{d}$ during the entire carryover period compared with the other 3 diets. Overall, SFFA supplementation tended to decrease milk yield with no effect on $3.5 \%$ FCM 
Table 5. Effects of dietary forage NDF (fNDF) content and a saturated free FA supplement (SFFA) fed during the immediate postpartum period on DMI and production of dairy cows when fed a common diet during the carryover period (30 to $71 \mathrm{~d}$ postpartum)

\begin{tabular}{|c|c|c|c|c|c|c|c|c|c|c|c|}
\hline \multirow[b]{2}{*}{ Item } & \multicolumn{2}{|c|}{$20 \% \mathrm{fNDF}$} & \multicolumn{2}{|c|}{$26 \% \mathrm{fNDF}$} & \multirow[b]{2}{*}{ SEM } & \multicolumn{6}{|c|}{$P$-value } \\
\hline & $\begin{array}{c}0 \% \\
\text { SFFA }\end{array}$ & $\begin{array}{l}2 \% \\
\text { SFFA }\end{array}$ & $\begin{array}{c}0 \% \\
\text { SFFA }\end{array}$ & $\begin{array}{l}2 \% \\
\text { SFFA }\end{array}$ & & $\mathrm{fNDF}$ & SFFA & $\begin{array}{l}\text { fNDF } \\
\times \text { SFFA }\end{array}$ & $\begin{array}{l}\text { fNDF } \\
\times \text { time }\end{array}$ & $\begin{array}{l}\text { SFFA } \\
\times \text { time }\end{array}$ & $\begin{array}{l}\mathrm{fNDF} \times \mathrm{SFFA} \\
\times \text { time }\end{array}$ \\
\hline DMI, $\mathrm{kg} / \mathrm{d}$ & 31.5 & 29.4 & 29.1 & 30.2 & 0.945 & 0.41 & 0.62 & 0.10 & 0.73 & 0.12 & 0.13 \\
\hline Cumulative DMI, $\mathrm{kg}$ & 1,321 & 1,224 & 1,218 & 1,266 & 39.8 & 0.44 & 0.53 & 0.07 & $\mathrm{NA}^{1}$ & NA & NA \\
\hline \multicolumn{12}{|l|}{ Yield, kg/d } \\
\hline Milk & 58.4 & 50.4 & 58.0 & 56.7 & 2.32 & 0.20 & 0.05 & 0.15 & 0.56 & 0.58 & 0.73 \\
\hline Fat & 2.06 & 1.80 & 2.03 & 2.10 & 0.103 & 0.20 & 0.34 & 0.10 & 0.34 & 0.45 & 0.22 \\
\hline Protein & 1.62 & 1.44 & 1.57 & 1.58 & 0.055 & 0.47 & 0.11 & 0.09 & 0.31 & 0.53 & 0.18 \\
\hline Lactose & 2.89 & 2.52 & 2.84 & 2.80 & 0.114 & 0.29 & 0.07 & 0.15 & 0.38 & 0.65 & 0.76 \\
\hline $3.5 \% \mathrm{FCM}$ & 58.7 & 51.1 & 58.0 & 58.5 & 2.47 & 0.17 & 0.16 & 0.10 & 0.37 & 0.89 & 0.44 \\
\hline $\mathrm{ECM}$ & 57.3 & 50.1 & 56.4 & 56.9 & 2.27 & 0.20 & 0.15 & 0.09 & 0.36 & 0.96 & 0.42 \\
\hline Cumulative milk yield, kg & 2,484 & 2,126 & 2,430 & 2,374 & 99.7 & 0.34 & 0.05 & 0.14 & $\mathrm{NA}$ & NA & NA \\
\hline Feed efficiency ${ }^{2}$ & 1.88 & 1.75 & 2.01 & 1.95 & 0.078 & 0.03 & 0.19 & 0.68 & 0.63 & 0.55 & 0.57 \\
\hline \multicolumn{12}{|l|}{ Milk composition, \% } \\
\hline Fat & 3.56 & 3.61 & 3.51 & 3.71 & 0.130 & 0.82 & 0.29 & 0.54 & 0.46 & 0.05 & 0.22 \\
\hline Protein & 2.79 & 2.89 & 2.72 & 2.80 & 0.051 & 0.11 & 0.09 & 0.75 & 0.72 & 0.90 & 0.54 \\
\hline Lactose & 4.95 & 4.99 & 4.90 & 4.95 & 0.042 & 0.26 & 0.32 & 0.98 & 0.12 & 0.57 & 0.78 \\
\hline MUN, mg/dL & 16.4 & 16.5 & 16.8 & 16.2 & 0.577 & 0.88 & 0.50 & 0.33 & 0.98 & 0.13 & 0.20 \\
\hline $\mathrm{SCC}, \times 1,000 / \mathrm{mL}$ & 89.4 & 114 & 102 & 127 & 76.0 & 0.86 & 0.73 & 1.00 & 0.20 & 0.43 & 0.77 \\
\hline $\mathrm{BW},{ }^{3} \hat{\mathrm{kg}}$ & 741 & 715 & 658 & 675 & 21.8 & $<0.01$ & 0.82 & 0.24 & 0.29 & 0.07 & 0.59 \\
\hline BW change ${ }^{4}$ & -1.70 & 13.8 & 1.70 & 7.17 & 6.08 & 0.77 & 0.07 & 0.38 & NA & NA & NA \\
\hline $\mathrm{BCS}^{3}$ & 2.50 & 2.90 & 2.02 & 2.34 & 0.156 & $<0.001$ & 0.02 & 0.78 & 0.10 & 0.51 & 0.80 \\
\hline BCS change ${ }^{4}$ & -0.135 & -0.073 & -0.205 & -0.198 & 0.074 & 0.19 & 0.63 & 0.70 & $\mathrm{NA}$ & NA & NA \\
\hline \multirow{2}{*}{\multicolumn{12}{|c|}{$\begin{array}{l}{ }^{1} \text { Not applicable. } \\
{ }^{2} 3.5 \% \text { FCM }(\mathrm{kg} / \mathrm{d}) / \mathrm{DMI}(\mathrm{kg} / \mathrm{d}) .\end{array}$}} \\
\hline & & & & & & & & & & & \\
\hline \multicolumn{12}{|c|}{$\begin{array}{l}{ }^{3} \text { Because of infinite likelihood with first-order autoregressive, the variance-covariance structure used to analyze BW and BCS was unstructured and compound symmetry, respe } \\
\text { tively. }\end{array}$} \\
\hline \multicolumn{12}{|c|}{${ }^{4}$ Change measured between d 68 and 33 . } \\
\hline
\end{tabular}


Table 6. Effects of dietary forage NDF (fNDF) content and a saturated free FA supplement (SFFA) on total-tract digestibility of nutrients of dairy cows during the treatment period (1 to $29 \mathrm{~d}$ postpartum)

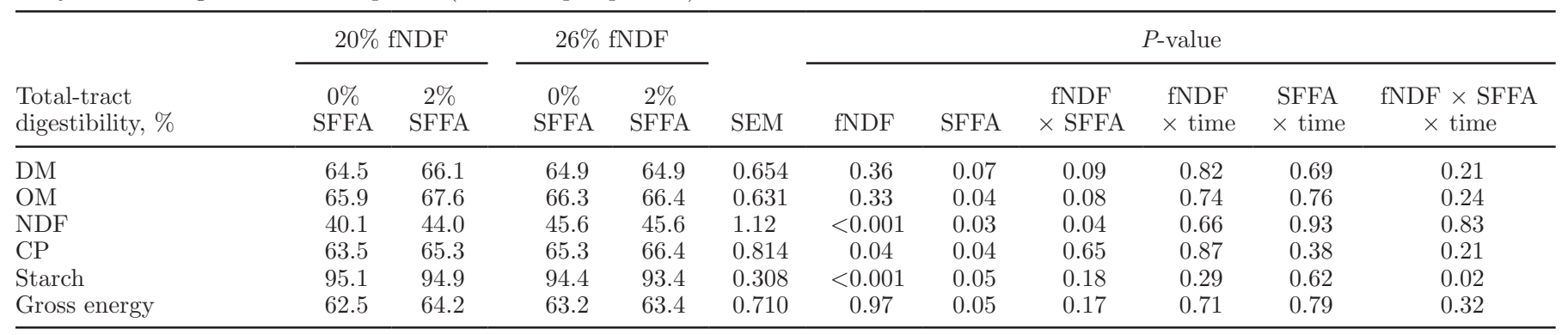

or ECM during the treatment period and decreased milk yield during the carryover period, but this effect was mainly due to the low-fNDF diet with $2 \%$ SFFA added. Even though milk yield was numerically lower for the low-fNDF diet with $2 \%$ SFFA during the first days postpartum (Figure 2), cows seemed to reach a lower peak milk yield that happened earlier in lactation compared with the other groups and this effect was sustained after cows were switched to a common diet during the carryover period. The $2 \%$ SFFA and low-

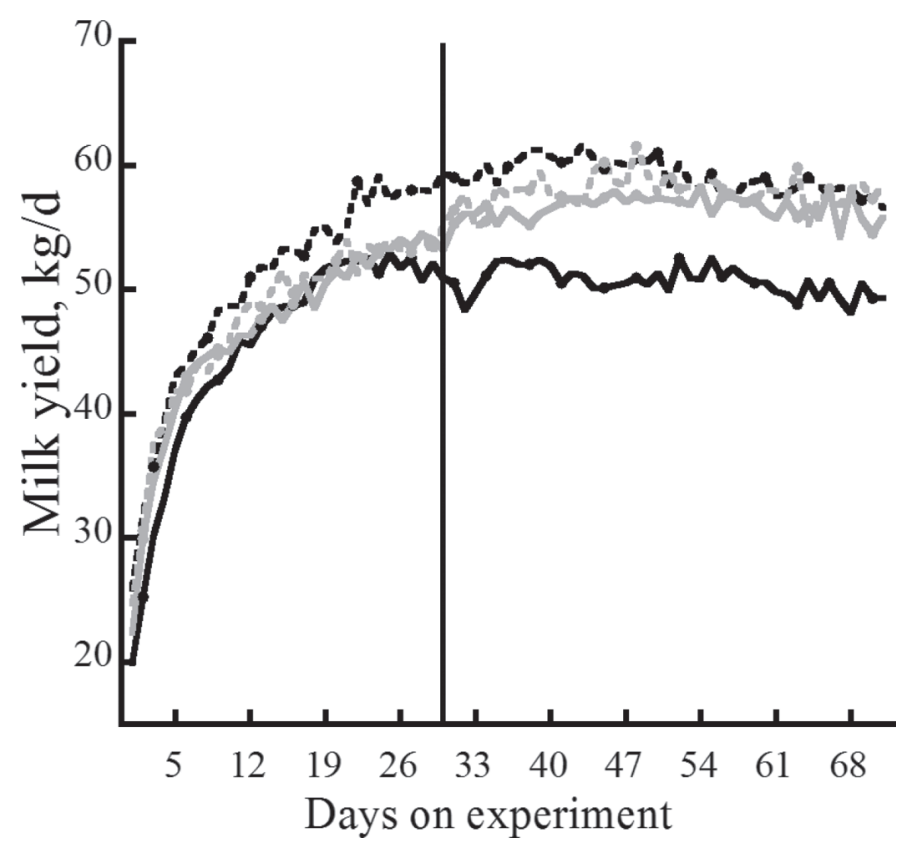

Figure 2. Effects of dietary forage NDF (fNDF) content and a saturated free FA supplement (SFFA) on milk yield over time during the treatment and carryover periods. Treatment diets were: $20 \%$ fNDF, 0\% SFFA (black, broken line); $20 \%$ fNDF, 2\% SFFA (black, solid line); $26 \%$ fNDF, $0 \%$ SFFA (gray, broken line); and $26 \%$ fNDF, $2 \%$ SFFA (gray, solid line). Daily averages for treatment groups were calculated with the raw data of 12 cows per treatment diet during both the treatment and carryover periods $(\mathrm{n}=11$ for $26 \% \mathrm{fNDF}, 2 \%$ SFFA during the carryover period). The line on $\mathrm{d} 30$ indicates the start of the carryover period, when all cows were fed a common diet with no supplemental fat added.
fNDF diets continued to have higher BCS during the carryover period, but BCS change during this period was not affected by diet, and, therefore, the effect on overall BCS observed was due to differences obtained during the treatment period. When comparing our results with those from early lactation cows reported by Weiss and Pinos-Rodríguez (2009), we found that the same fat supplement increased energy partitioned to body condition and not milk for high-fNDF diets in both experiments, but results differed between experiments when fat was supplemented in the low-fNDF diets. In that experiment, supplementation of FA in the low-fNDF diet partitioned energy to milk rather than body reserves, which is the opposite of what happened during the treatment period in our experiment. In addition, FA supplementation in the low-fNDF diet increased DMI early but decreased it later in the treatment period compared with the low-fNDF diet with supplemental fat in the experiment of Weiss and PinosRodríguez (2009). Moreover, and consistent with our results, they showed that fat supplementation increased DMI in the high-fNDF diet during most of the treatment period, compared with the high-fNDF diet with no supplemental fat. Even though cows used by Weiss and Pinos-Rodríguez (2009) had lower peak milk yield than cows used in our experiment ( $\sim 50$ vs. $\sim 60 \mathrm{~kg} / \mathrm{d})$ and their low-fNDF treatment diet was lower than what we used (17 vs. $20 \%$ fNDF), the most likely reason for the discrepancy in results is the different physiological state of the cows (early lactation vs. immediate postpartum cows).

Other studies have reported supplementation of saturated prilled FA at different levels of dietary forage and results are inconsistent. Jerred et al. (1990) added a saturated prilled fat supplement at $5 \%$ of dietary DM to diets varying in F:C from d 5 postpartum and for $100 \mathrm{~d}$ and did not detect interactions between forage level and fat supplementation for DMI, milk yield, $4 \%$ FCM yield, BW change, or any other response measured. In contrast, Grum et al. (1996) fed diets with 2 different levels of concentrate (resulting in $\sim 33$ vs. 
Table 7. Effects of dietary forage NDF (fNDF) content and a saturated free FA supplement (SFFA) on yields and profile of milk FA summed by source ${ }^{1}$ of dairy cows during the treatment period ( 1 to $29 \mathrm{~d}$ postpartum)

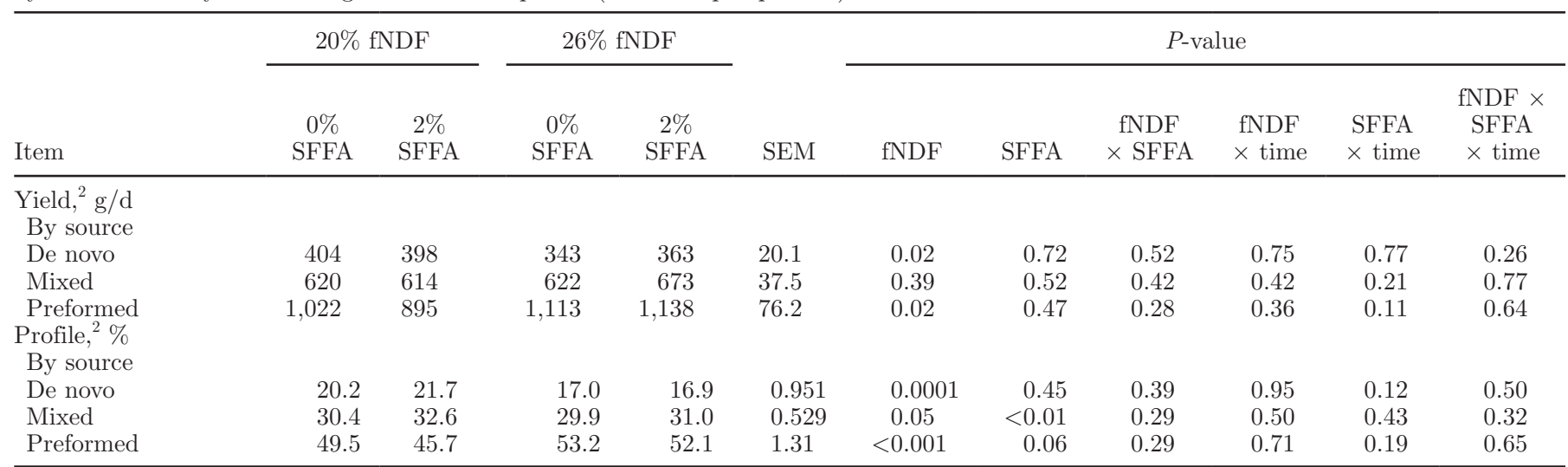

${ }^{1}$ De novo FA originate from mammary de novo synthesis ( $<16$ carbons), preformed FA originate from extraction from plasma $(>16$ carbons), and mixed FA originate from both sources (C16:0 plus C16:1 cis-9; Bauman and Griinari, 2003).

${ }^{2} \mathrm{~A}$ total of approximately 80 individual FA were quantified and used for calculations (summation by source).

$\sim 28 \%$ NDF diets) with or without fat supplementation (3\% saturated prilled FA supplement plus $10 \%$ whole raw soybeans) to early- and mid-lactation cows averaging $\sim 28 \mathrm{~kg}$ of milk/d and detected an interaction between concentrate level and fat addition for DMI, but not for milk yield or 4\% FCM. The interaction indicated that supplemental fat increased DMI when fed in the high-NDF diet (20.7 vs. $19.2 \mathrm{~kg} / \mathrm{d}$ ), which is in agreement with our results, but decreased DMI when fed in the low-NDF diet (19.4 vs. $20.2 \mathrm{~kg} / \mathrm{d})$, which is inconsistent with our results. However, the amount of fat supplemented was greater and of mixed source.

\section{Dry Matter Intake}

The negative effect of diets with higher fNDF on DMI during the postpartum and early lactation periods has been documented and reviewed previously (Allen, 1996). Rabelo et al. (2003) reported that a higher forage diet (30\% NDF) tended to decrease DMI compared with a lower-forage diet (25\% NDF; 15.4 vs. $16.5 \mathrm{~kg} / \mathrm{d}$; $P=0.10)$ during the first $20 \mathrm{~d}$ postpartum. Forage fiber clears from the rumen more slowly than other diet fractions and is therefore more filling over time in the rumen. Signals from ruminal distension can dominate control of feed intake when the filling effect of the diet is high enough. Although feed intake is likely controlled primarily by mechanisms related to oxidation of fuels in the liver in early postpartum (Allen and Piantoni, 2013), rumen distension likely dominated control of intake for the high-fNDF treatment in the current experiment. During the treatment period and regardless of dietary fNDF content, supplemental SFFA increased DMI and tended to decrease plasma NEFA concentration (695 vs. $827 \mu \mathrm{Eq} / \mathrm{L} ; P=0.06$; data shown in Piantoni et al., 2015b). Furthermore, the effect on plasma NEFA concentration was more pronounced at the beginning of the treatment period (interaction $P=0.05$ ). The increase in DMI observed with fat supplementation might be related to a decreased flux of fuels to the liver that could have potentially decreased satiety and improved DMI (Allen et al., 2009).

\section{Saturated Fat Supplementation During the Postpartum Period}

Production responses to saturated fat supplementation postpartum have been inconsistent. Moallem et al. (2007) fed the same FA supplement used in our experiment but at approximately half the inclusion rate $(230$ $\mathrm{g} / \mathrm{d}$ ) during the dry period and the first $21 \mathrm{~d}$ postpartum ( $19 \%$ fNDF lactating diet) and showed that fat supplementation decreased DMI postpartum (18.4 vs. $19.8 \mathrm{~kg} / \mathrm{d} ; P<0.05)$, but did not affect yields of milk and milk components or changes in BW and BCS compared with a control diet with no supplemental fat. Because they started feeding the FA supplement during the prepartum period (from $256 \mathrm{~d}$ pregnant), the effect of fat supplementation on productive performance during the first weeks postpartum cannot be discerned from a possible carryover effect from the prepartum period. In addition, Beam and Butler (1998) supplemented the same FA supplement used in the current experiment at $2.6 \%$ of diet DM in a $\sim 33 \%$ NDF diet and reported no effect on DMI $(P=0.13)$ during the first 6 wk postpartum, when compared with a control diet with no supplemental fat added. However, and consistent with Moallem et al. (2007), fat supplementation decreased 
DMI compared with the control diet when only the first 4 wk postpartum were considered (15.5 vs. $17.3 \mathrm{~kg} / \mathrm{d}$; $P<0.05)$. In addition, an interaction between diet and week was detected for yields of $4 \%$ FCM and milk; fat supplementation decreased yields of $4 \%$ FCM and milk during the first $3 \mathrm{wk}$ postpartum, but increased them later during the treatment period $(P<0.10)$.

\section{Feed Efficiency}

The SFFA treatment decreased FE overall during the treatment period, but especially in the low-fNDF diet, which decreased FE earlier but not later in the treatment period compared with the other diets. The decrease in $\mathrm{FE}$ was therefore related to the reduction in mobilization of body reserves. In contrast, the higher-fNDF diets increased FE overall, but especially earlier in the treatment period, and this was related to increased energy partitioned to milk production, with increased BCS loss and decreased DMI. For cows past peak lactation, saturated fat supplements have increased $\mathrm{FE}$, either by decreasing DMI with no effect on milk yield (Lock et al., 2013; Rico et al., 2014) or by increasing milk yield with no effect on DMI (Wang et al., 2010; Piantoni et al., 2013). In early lactation cows, Weiss and Pinos-Rodríguez (2009) showed that fat supplemented in the low-fNDF diet increased FE because of an increase in milk yield, but when supplemented in the high-fNDF diet decreased FE because of an increase in body condition. In postpartum cows, a decrease in $\mathrm{FE}$ might be desirable if milk production is maintained and DMI is increased, which would indicate a decrease in mobilization of body reserves. In the current experiment, during the treatment period, fat supplementation decreased FE regardless of fNDF content of the diet, and this was related to a greater DMI and a decrease in BCS loss.

\section{Milk Components and Fatty Acids}

Higher-forage diets with higher fNDF and lower starch contents often increase milk fat concentration (Jerred et al., 1990). In the current experiment, higher fNDF tended to increase milk fat concentration and tended to interact with SFFA and time to affect milk protein yield, and low fNDF with $0 \%$ SFFA had greater milk protein yield compared with the other diets throughout the treatment period. An increase in milk protein yield might be a result of greater rumen microbial protein reaching the duodenum for absorption because of the greater supply of ruminally fermentable energy. We did not detect an effect of SFFA supplementation on milk fat percent or milk fat yield during the treatment period, in contrast to other experiments supplementing the commercial FA used in our experiment (Wang et al., 2010). Moreover, SFFA treatment decreased yields of preformed FA in milk during the first week but not later during the treatment period, and the secretion pattern of preformed FA in milk followed that of plasma NEFA concentrations (Piantoni et al., 2015b), consistent with the concept that greater milk fat output following parturition is from mobilization of adipose reserves (Kronfeld, 1965). In contrast, high-fNDF diets increased yields of preformed FA in milk and decreased de novo FA yields, which might be related to the increased BCS loss and decreased DMI, respectively, observed with these diets.

\section{Total-Tract Digestibility of Nutrients}

Effects of SFA supplements on digestibility of dietary components are inconsistent across experiments. In our experiment, SFFA supplementation increased NDF digestibility by $9.7 \%$ in the low-fNDF diet, but had no effect in the high-fNDF diet. In agreement, a $99 \%$ pure palmitic acid supplement fed in a $19 \%$ fNDF diet at $2 \%$ of diet DM increased NDF digestibility by $9.2 \%(P<$ 0.001 ) when compared with a diet with no supplemental fat in cows past peak lactation (Piantoni et al., 2013). In that experiment, we showed that palmitic acid increased plasma concentration of cholecystokinin, a gut peptide responsible for decreasing abomasal motility, and speculated that the increase in NDF digestibility observed was related to increased retention time in the rumen (Piantoni et al., 2013). In addition, Piantoni et al. (2015a) showed that a $98 \%$ pure stearic acid supplement fed in a $24.5 \%$ fNDF diet at $2 \%$ of diet DM tended to increase NDF digestibility by $3.1 \%(P=0.10)$ when compared with a diet with no supplemental fat in cows past peak lactation. Also consistent with our results, supplementation of saturated FA did not affect nutrient digestibility when supplemented in a high-forage diet $(\sim 42 \% \mathrm{NDF})$ in late lactation cows (Schauff and Clark, 1989). However, a saturated FA supplement had no effect on NDF digestibility when fed to cows past peak lactation in a $17 \%$ fNDF diet (Harvatine and Allen, 2006b) or across fNDF contents when fed to cows in the postpartum period and in early lactation (Jerred et al., 1990), which is inconsistent with our results. Furthermore, a saturated FA supplement increased digestibility of OM and CP when supplemented to cows past peak lactation in a higher-forage diet (33\% NDF), but decreased them when supplemented in a lower-forage $\operatorname{diet}(28 \%$ NDF; Grum et al., 1996). Effects of saturated FA supplementation on nutrient digestibility are likely dependent upon FA composition and its interaction 
with dietary components, which will likely affect gut peptide release and their effects on retention time of digesta in the rumen.

\section{CONCLUSIONS}

Supplementation of SFFA during the immediate PP favored energy partitioning to body reserves rather than milk yield, especially in the lower-fNDF diet. The highfNDF diet with supplemental SFFA increased DMI and tended to decrease BCS compared with the same diet without SFFA. The low-fNDF diet with supplemental SFFA increased DMI and digestibility of OM and tended to decrease BCS loss, but reduced milk yield compared with the other diets. Regardless of fNDF content, supplemental SFFA during the PP increased DMI, decreased BCS loss, but tended to decrease milk yield, and, therefore, decreased FE. Supplementation of SFFA did not affect yields of 3.5\% FCM, ECM, and milk fat during the PP. When cows were fed a common diet during the carryover period, the low-fNDF treatment with $2 \%$ SFFA that was fed during the PP continued to decrease milk yield and maintained higher BCS compared with the other 3 diets, but did not affect DMI, BCS loss, or FE. In general, SFFA supplementation alleviated the deleterious effects of feeding a highfNDF diet on DMI during the first $30 \mathrm{~d}$ postpartum. However, supplementing SFFA in the lower-fNDF diet during the immediate postpartum period limited milk yield in the carryover period.

\section{ACKNOWLEDGMENTS}

We acknowledge Milk Specialties Global (Eden Prairie, MN) and Michigan AgBioResearch (East Lansing, MI) for financial support of this research. We also thank D. G. Main, R. A. Longuski, C. L. Preseault, S. E. Stocks, W. E. Brown, R. J. Rockwell, and R. E. Kreft (all from Michigan State University), as well as the staff of the Michigan State University Dairy Cattle Field Laboratory (East Lansing) for their assistance in this experiment, and West Central Soy for supplying the SoyPlus used during the experiment.

\section{REFERENCES}

Allen, M. S. 2000. Effects of diet on short-term regulation of feed intake by lactating dairy cattle. J. Dairy Sci. 83:1598-1624.

Allen, M. S., B. Bradford, and M. Oba. 2009. Board-invited review: The hepatic oxidation theory of the control of feed intake and its application to ruminants. J. Anim. Sci. 87:3317-3334.

Allen, M. S. 1996. Physical constraints on voluntary intake of forages by ruminants. J. Anim. Sci. 74:3063-3075.

Allen, M. S., and P. Piantoni. 2013. Metabolic control of feed intake: Implications for metabolic disease of fresh cows. Vet. Clin. North Am. Food Anim. Pract. 29:279-297.
AOAC International. 1997. Official Methods of Analysis. 16th ed. AOAC International, Gaithersburg, MD.

AOAC International. 2005. Official Methods of Analysis. 18th ed. AOAC International, Gaithersburg, MD.

Bauman, D. E., and J. M. Griinari. 2003. Nutritional regulation of milk fat synthesis. Annu. Rev. Nutr. 23:203-227.

Baumgard, L. H., B. Corl, D. Dwyer, and D. Bauman. 2002. Effects of conjugated linoleic acids (CLA) on tissue response to homeostatic signals and plasma variables associated with lipid metabolism in lactating dairy cows. J. Anim. Sci. 80:1285-1293.

Beam, S. W., and W. R. Butler. 1998. Energy balance, metabolic hormones, and early postpartum follicular development in dairy cows fed prilled lipid. J. Dairy Sci. 81:121-131.

Christie, W. W. 1989. Gas Chromatography and Lipids: A Practical Guide. The Oily Press, Ayr, Scotland.

Cochran, R. C., D. C. Adams, J. D. Wallace, and M. L. Galyean. 1986. Predicting the digestibility of different diets with internal markers: evaluation of four potential markers. J. Anim. Sci. 63:1476-1483.

Glasser, F., M. Doreau, A. Ferlay, and Y. Chilliard. 2007. Technical note: Estimation of milk fatty acid yield from milk fat data. J. Dairy Sci. 90:2302-2304.

Goering, H. K., and P. J. Van Soest. 1970. Forage Fiber Analysis (Apparatus, Reagents, Procedures, and Some Applications). Agricultural Handbook no. 379. Agricultural Research Service-USDA, Washington, DC.

Grum, D. E., J. K. Drackley, L. R. Hansen, and J. D. Cremin Jr.. 1996. Production, digestion, and hepatic lipid metabolism of dairy cows fed increased energy from fat or concentrate. J. Dairy Sci. 79:1836-1849.

Grummer, R. R. 1988. Influence of prilled fat and calcium salt of palm oil fatty acids on ruminal fermentation and nutrient digestibility. J. Dairy Sci. 71:117-123.

Hach, C. C., B. K. Bowden, A. B. Lopelove, and S. V. Brayton. 1987. More powerful peroxide Kjeldahl digestion method. J. Assoc. Off. Anal. Chem. 70:783-787.

Hara, A., and N. S. Radin. 1978. Lipid extraction of tissues with a low-toxicity solvent. Anal. Biochem. 90:420-426.

Harvatine, K. J., and M. Allen. 2006a. Effects of fatty acid supplements on milk yield and energy balance of lactating dairy cows. J. Dairy Sci. 89:1081-1091.

Harvatine, K. J., and M. S. Allen. 2006b. Effects of fatty acid supplements on ruminal and total-tract nutrient digestion in lactating dairy cows. J. Dairy Sci. 89:1092-1103.

Harvatine, K. J., J. W. Perfield, and D. E. Bauman. 2009. Expression of enzymes and key regulators of lipid synthesis is upregulated in adipose tissue during CLA-induced milk fat depression in dairy cows. J. Nutr. 139:849-854.

Jerred, M. J., D. J. Carrol, D. K. Combs, and R. R. Grummer. 1990. Effects of fat supplementation and immature alfalfa to concentrate ratio on lactation performance of dairy cattle. J. Dairy Sci. $73: 2842-2854$.

Karkalas, J. 1985. An improved enzymatic method for the determination of native and modified starch. J. Sci. Food Agric. 36:10191027.

Kronfeld, D. S. 1965. Plasma non-esterified fatty acid concentrations in dairy cows: Responses to nutritional and hormonal stimuli, and significance in ketosis. Vet. Rec. 77:30-35.

Lammers, B. P., D. R. Buckmaster, and A. J. Heinrichs. 1996. A simple method for the analysis of particle sizes of forage and total mixed rations. J. Dairy Sci. 79:922-928.

Lock, A. L., C. L. Preseault, J. E. Rico, K. E. DeLand, and M. S. Allen. 2013. Feeding a C16:0-enriched fat supplement increased the yield of milk fat and improved feed efficiency. J. Dairy Sci. 96:6650-6659

Mertens, D. R. 2002. Gravimetric determination of amylase-treated neutral detergent fiber in feeds using refluxing in beakers or crucibles: collaborative study. J. AOAC Int. 85:1217-1240.

Moallem, U., M. Katz, H. Lehrer, L. Livshitz, and S. Yakoby. 2007. Role of peripartum dietary propylene glycol or protected fats on metabolism and early postpartum ovarian follicles. J. Dairy Sci. 90:1243-1254. 
NRC. 2001. Nutrient Requirements of Dairy Cattle. 7th rev. ed. Natl. Acad. Press, Washington, DC.

Piantoni, P., A. L. Lock, and M. S. Allen. 2013. Palmitic acid increased yields of milk and milk fat and nutrient digestibility across production level of lactating cows. J. Dairy Sci. 96:7143-7154.

Piantoni, P., A. L. Lock, and M. S. Allen. 2015b. Saturated fat supplementation interacts with dietary forage NDF content during the immediate postpartum in Holstein cows: Energy balance and metabolism. J. Dairy Sci. 98:3323-3334. 10.3168/jds.2014-8799.

Pires, J. A. A., and R. R. Grummer. 2008. Specific fatty acids as metabolic modulators in the dairy cow. R. Bras. Zootec. 37:287-298.

Rabelo, E., R. L. Rezende, S. J. Bertics, and R. R. Grummer. 2003. Effects of transition diets varying in dietary energy density on lactation performance and ruminal parameters of dairy cows. J. Dairy Sci. 86:916-925.

Rico, D. E., Y. Ying, and K. J. Harvatine. 2014. Effect of a high-palmitic acid fat supplement on milk productionand apparent totaltract digestibility in high- and low-milk yield dairy cows. J. Dairy Sci. 97:3739-3751.
Schauff, D. J., and J. H. Clark. 1989. Effects of prilled fatty acids and calcium salts of fatty acids on rumen fermentation, nutrient digestibilities, milk production, and milk composition. J. Dairy Sci. 72:917-927.

Schauff, D. J., J. P. Elliott, J. H. Clark, and J. K. Drackley. 1992. Effects of feeding lactating dairy cows diets containing whole soybeans and tallow. J. Dairy Sci. 75:1923-1935.

Wang, J. P., D. Bu, J. Wang, X. Huo, and T. Guo. 2010. Effect of saturated fatty acid supplementation on production and metabolism indices in heat-stressed mid-lactation dairy cows. J. Dairy Sci. 93:4121-4127.

Weiss, W. P., and J. M. Pinos-Rodríguez. 2009. Production responses of dairy cows when fed supplemental fat in low- and high-forage diets. J. Dairy Sci. 92:6144-6155.

Wildman, E. E., G. M. Jones, P. E. Wagner, R. L. Boman, H. F. Troutt Jr., and T. N. Lesch. 1982. A dairy cow body condition scoring system and its relationship to selected production characteristics. J. Dairy Sci. 65:495-501. 